This PDF is a selection from a published volume from the National Bureau of Economic Research

Volume Title: Labor Markets and Firm Benefit Policies in Japan and the United States

Volume Author/Editor: Seiritsu Ogura, Toshiaki Tachibanaki and David A. Wise, editors

Volume Publisher: University of Chicago Press

Volume ISBN: 0-226-62094-8

Volume URL: http://www.nber.org/books/ogura03-1

Conference Date: January 20-23, 2000

Publication Date: January 2003

Title: Total Labor Costs and the Employment Adjustment Behavior of Large Japanese Firms

Author: Yoshifumi Nakata, Ryoji Takehiro

URL: http://www.nber.org/chapters/c10305 


\title{
Total Labor Costs and the Employment Adjustment Behavior of Large Japanese Firms
}

\author{
Yoshifumi Nakata and Ryoji Takehiro
}

\subsection{Introduction}

Employment instability has recently become a prominent social issue in Japan. It is widely believed that Japanese firms, particularly large firms, are committed to stable employment even in the face of unfavorable economic conditions. If firms are unable to absorb demand fluctuations by adjusting working hours, they adjust employment levels by restricting the inflow of new workers and encouraging older workers to retire early, rather than by laying off employees. Increasingly, however, this employment practice is being criticized as the major cause of the prolonged recession.

In response to the growing interest in this topic, a number of recent studies have investigated employment instability in large Japanese firms. These studies, which employ newly available firm-level panel data sets, include Suruga (1997), Noda (1998), Noda and Urasaka (2001), Okui (2000), and Nakata and Takehiro (2001). Typically, some type of partial adjustment model is used to examine the mechanisms through which employment adjusts. These studies find that a firm's size and elements of its governance structure, such as type of ownership and industrial relations policies, are important in explaining its employment adjustment behavior.

However, the methodology of these types of partial adjustment models has been questioned. Hamermesh (1989), for example, showed that fixed cost considerations are necessary for explaining large, lumpy changes in plant-level employment in his sample of manufacturing firms. Partial adjustment models, which assume a smooth, quadratic adjustment cost func-

Yoshifumi Nakata is dean and professor of management in Doshisha Management School. Ryoji Takehiro is associate professor of economics, Doshisha University. 
tion, are therefore not suitable for analyzing lumpy employment adjustment that occurs at the plant level.

All of the above studies analyze samples of manufacturing firms only, ${ }_{1}$ and, with the exception of Suruga (1997), they all apply the partial adjustment model without investigating the implications thereof. In addition, the current literature fails to address two important empirical facts. First, it is well established that Japanese firms make extensive use of their ability to adjust individual work hours. Indeed, overtime work is regularly observed even in periods of low demand. ${ }^{2}$ Second, with the exception of Okui (2000), there is a complete lack of nonwage labor cost data in the Japanese literature. ${ }^{3}$ However, there are reasons to expect Japanese employers to consider fringe benefit costs in addition to wage costs when choosing their optimal labor demand. For example, the rapid aging of the Japanese population has increased employers' social security contributions in the last decade, and this trend is expected to continue through the current decade. It is impossible to properly evaluate the employment adjustment behavior of Japanese employers without taking all of these considerations into account.

We construct a firm-level panel data set of total labor costs and hours worked over a period of twenty-five years. The data cover firms in nonmanufacturing industries as well as automobile assembly firms, which were chosen as representative of the manufacturing industry. This new data set enables us to analyze the employment adjustment behavior of Japanese firms from a broader perspective.

Specifically, our analysis consists of the following:

1. We construct a firm-level panel data set of thirty-three major Japanese firms over twenty-five years. This data set is rare in that it includes consistent employment data over the entire time period. By studying the frequency and magnitude of large-scale employment adjustment in this data, we examine the commonly held view that large Japanese firms are committed to employment stability.

2. We expand the scope of investigation beyond the manufacturing industry by including department stores and supermarkets in the dataset. This allows us to compare employment adjustment patterns across industries as well as within industries.

3. We use total labor costs per capita rather than average monthly salary to measure the factor price when estimating the partial adjustment model.

1. Although there are numerous studies that examine interindustry differences in employment adjustment, they all use aggregate data, such as Kurosaka (1988). We only review studies using firm/establishment-level panel data.

2. Muramatsu (1983) is the first Japanese economist to examine this issue in detail. The sixth chapter of his book (Eichner, McClellan, and Wise) contains an exhaustive treatment of both the theoretical and empirical aspects of this topic.

3. Smith and Karlson (1991) incorporate nonwage cost data in examining the automobile industry, an industry we also study, in England. 
We then compare the relative suitability of the two measures within the context of the model.

4. We use information on hours worked, available for the subset of eleven automobile firms, to construct a measure of total labor input. This makes it possible for us to examine whether fluctuations in total labor input can be explained by the partial adjustment model.

We conclude by summarizing and interpreting our findings and discussing opportunities for future research.

\subsection{Employment Adjustment}

It is commonly believed that Japanese firms, particularly large firms, do not adjust their employment levels through layoffs unless they are faced with an extraordinary situation, such as bankruptcy. Rather, they adjust employment inflows, an easier margin to adjust than employment outflows. Given this limited adjustment leverage, it is very unlikely that a Japanese firm could trim its workforce, particularly its regular workforce, more than 5 percent per year. ${ }^{4}$ It is inconceivable for a firm to adjust employment in this way by more than 10 percent per year.

\subsubsection{Employment Data}

We examine this belief by looking at employment data for thirty-three major Japanese firms in the automobile assembly, department store, and supermarket sectors. The data come from two sources. One is an economic activities report, called Yukashouken Hokokusyo Soran (literally, "comprehensive report of valued commercial papers"), submitted by each of these firms to the Ministry of Finance at the end of every fiscal year. The other source is labor union reports on union members' working conditions. Summary statistics of each of the variables are presented separately by sector in table 5.1. The sample includes nearly all of the leading firms in these industries in Japan. Thus, the data are suitable for examining the employment adjustment behavior of major Japanese firms.

\subsubsection{Employment Adjustment Trends}

Table 5.2 presents a summary of employment changes of regular workers in the sample from 1975 to 1997. The following observations are noteworthy:

1. It is not uncommon for major firms in all three industries to reduce employment by more than 5 percent in a single fiscal year. In fact, only six of the thirty-three firms have never experienced such a large employment

4. Five percent is the average annual turnover rate of regular workers among large Japanese firms. 


\begin{tabular}{|c|c|c|c|c|c|}
\hline & $N$ & Mean & $\begin{array}{l}\text { Standard } \\
\text { Deviation }\end{array}$ & Minimum & Maximum \\
\hline \multicolumn{6}{|c|}{ Automobile Assembly Firms } \\
\hline Regular workers: total number & 12 & 22,442 & $18,448.84$ & 4,942 & 70,524 \\
\hline Regular workers: $\%$ female & 12 & 6.73 & 2.38 & 3.44 & 11.94 \\
\hline Average age: male workers & 12 & 39.27 & 1.79 & 36.3 & 43.00 \\
\hline Average age: female workers & 12 & 29.58 & 2.07 & 25.7 & 32.50 \\
\hline Average tenure: male workers & 12 & 17.01 & 3.39 & 7.90 & 21.20 \\
\hline Average tenure: female workers & 12 & 8.94 & 1.60 & 5.70 & 11.80 \\
\hline Sales per capita (million yen) & 12 & 78.03 & 18.40 & 58.01 & 110.17 \\
\hline Ordinary profit per capita (million yen) & 12 & 2.25 & 2.95 & -0.80 & 8.87 \\
\hline Average monthly wage (yen) & 12 & 381,541 & 30,803 & 345,676 & 444,599 \\
\hline Bonus over average monthly wage (monthly) & 11 & 4.18 & 0.41 & 3.51 & 4.88 \\
\hline Employment cost per capita (million yen) & 12 & 8.06 & 1.46 & 5.82 & 11.46 \\
\hline \multicolumn{6}{|c|}{ Department Stores } \\
\hline Regular workers: total number & 11 & $5,087.18$ & $3,672.59$ & 1,061 & 12,029 \\
\hline Regular workers: $\%$ female & 11 & 49.76 & 6.58 & 40.00 & 62.39 \\
\hline Average age: male workers & 11 & 42.17 & 1.89 & 38.80 & 44.90 \\
\hline Average age: female workers & 11 & 31.24 & 2.02 & 27.30 & 34.50 \\
\hline Average tenure: male workers & 11 & 20.33 & 2.88 & 13.60 & 24.30 \\
\hline Average tenure: female workers & 11 & 10.54 & 1.41 & 8.10 & 13.30 \\
\hline Sales per capita (million yen) & 11 & 73.60 & 9.74 & 56.27 & 91.24 \\
\hline Ordinary profit per capita (million yen) & 11 & 0.70 & 0.63 & 0.13 & 2.43 \\
\hline Average monthly wage (yen) & 11 & 346,696 & 43,398 & 257,162 & 413,101 \\
\hline Bonus over average monthly wage (monthly) & 9 & 4.25 & 0.56 & 3.55 & 5.27 \\
\hline Employment cost per capita (million yen) & 11 & 7.52 & 0.96 & 6.32 & 9.05 \\
\hline \multicolumn{6}{|c|}{ Supermarkets } \\
\hline Regular workers: total number & 10 & 7,495 & 5,736 & 431 & 16,686 \\
\hline Regular workers: $\%$ female & 10 & 34.49 & 11.71 & 8.61 & 51.75 \\
\hline Average age: male workers & 10 & 37.93 & 2.42 & 34.20 & 41.50 \\
\hline Average age: female workers & 10 & 28.81 & 3.33 & 24.80 & 35.70 \\
\hline Average tenure: male workers & 10 & 14.79 & 2.63 & 9.60 & 18.00 \\
\hline Average tenure: female workers & 10 & 7.88 & 2.27 & 5.40 & 11.90 \\
\hline Sales per capita (million yen) & 10 & 121.07 & 32.44 & 93.78 & 200.93 \\
\hline Ordinary profit per capita (million yen) & 10 & 1.40 & 1.79 & -1.55 & 4.66 \\
\hline Average monthly wage (yen) & 10 & 323,029 & 21,991 & 297,079 & 350,208 \\
\hline Bonus over average monthly wage (monthly) & 9 & 3.81 & 0.71 & 2.70 & 4.90 \\
\hline Employment cost per capita (million yen) & 10 & 10.65 & 1.74 & 6.94 & 12.55 \\
\hline
\end{tabular}

reduction, and most firms have experienced it more than once. A majority of our sample, twenty firms, has undergone such reductions at least twice in the last twenty-five years.

2. Most firms have experienced employment reductions much larger than 5 percent. Eleven of the thirty-three firms have trimmed their workforce in a given year by more than 10 percent. The average maximum oneyear reductions are 7.42 percent, 10.50 percent, and 14.37 percent in the automobile assembly, department store, and supermarket sectors respec- 


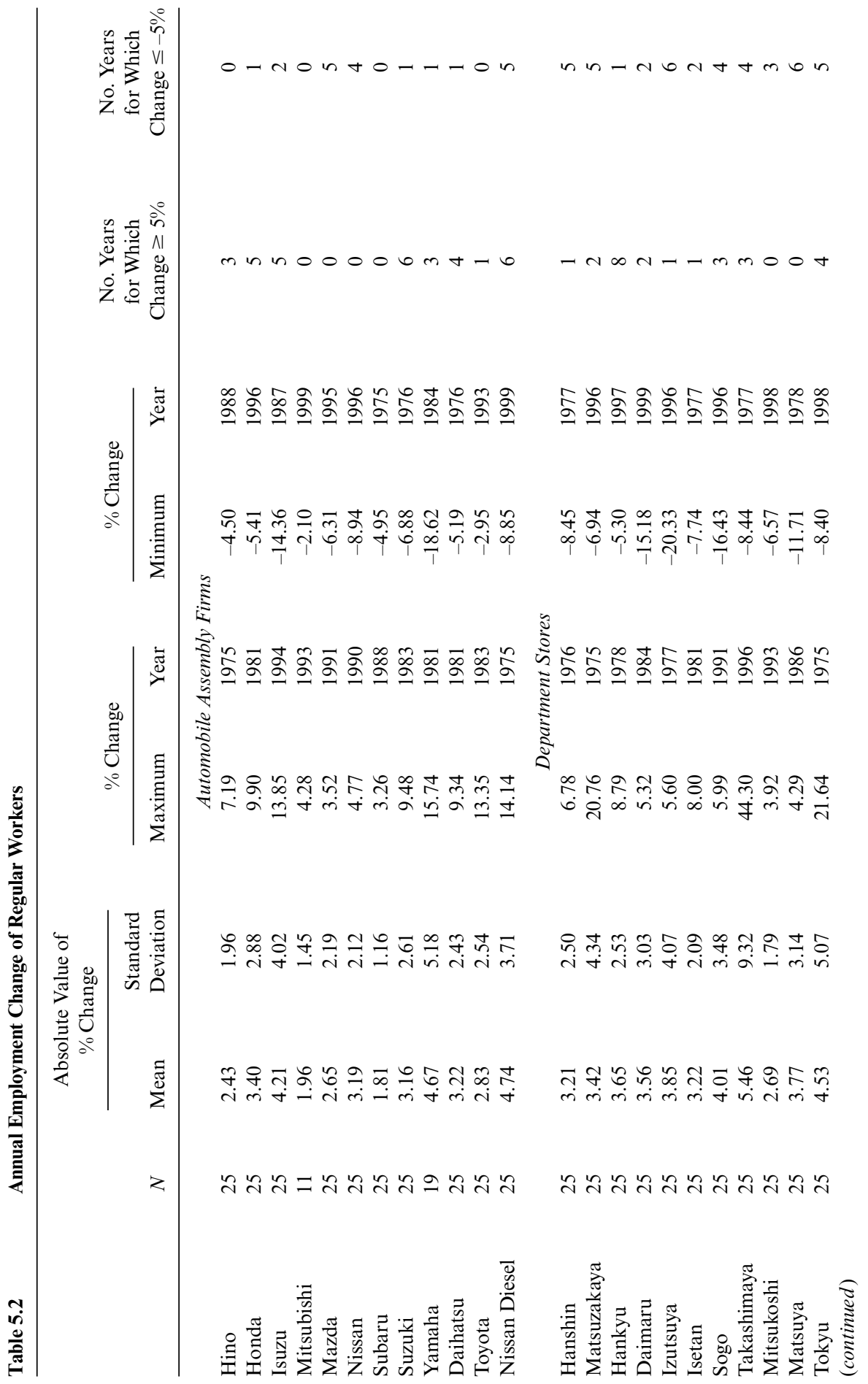




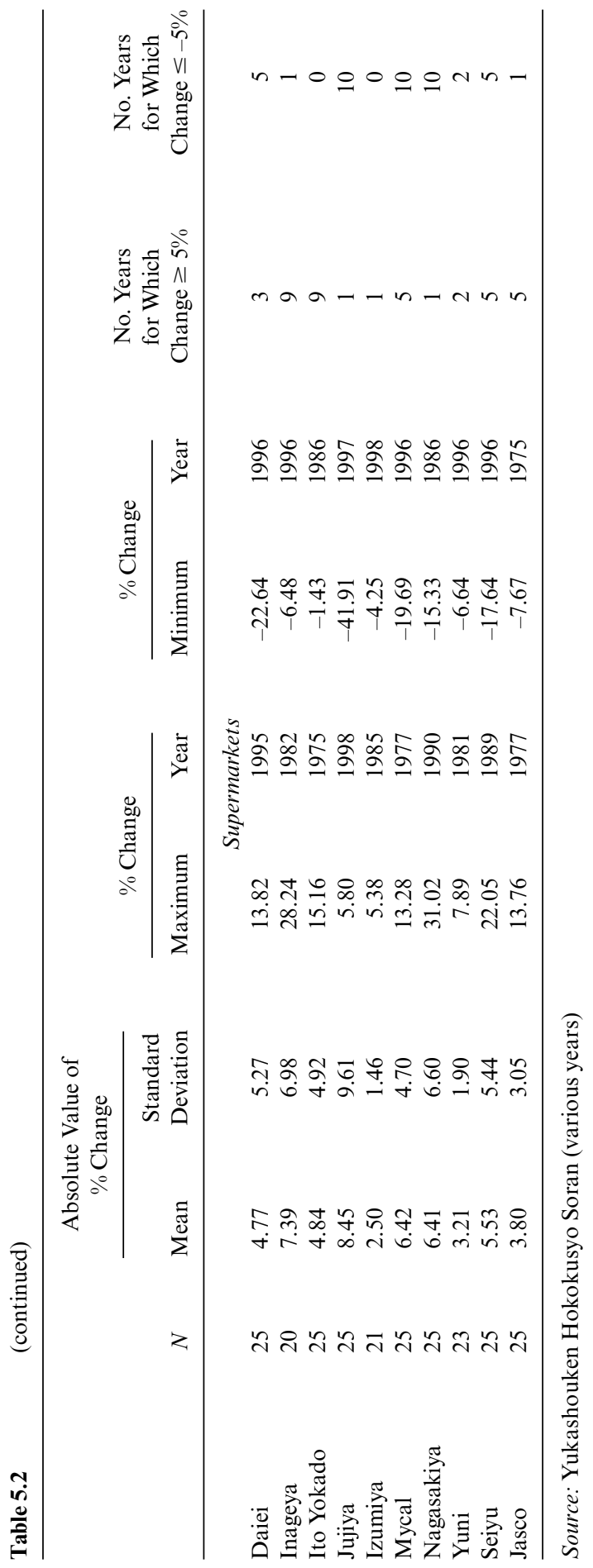


tively. This magnitude of employment reduction is unattainable through scaling back new recruitment alone, even if new recruitment were stopped entirely.

3. Large employment reductions are not confined to a single industry or time period. At least two firms in each industry have trimmed employment by more than 10 percent in a single year, and these large reductions are spread over the twenty-five years.

4. Large employment increases are as common as large employment decreases. The automobile assembly, department store, and supermarket companies in our sample experienced twenty-two, twenty-five, and fortyone single-year increases in employment of 5 percent or more, and twenty, forty-three, and forty-four single-year reductions in employment of 5 percent or more, respectively. Therefore, most firms experienced large-scale employment increases and decreases with roughly the same frequency.

These findings show that large employment reductions are common at leading Japanese firms, yet it is still widely believed that layoffs are very rare at these firms. We now proceed to analyze the employment adjustment of our sample firms in the context of a partial employment adjustment model.

\subsection{The Partial Employment Adjustment Model}

In order to understand the employment adjustment behavior of major Japanese firms, we use a partial employment adjustment model to estimate both a partial adjustment parameter and the elasticities of employment with respect to output and the relative wage.

\subsubsection{Discussion of Alternative Specifications}

The model is based on the assumption that a firm maximizes its expected future profit stream by minimizing a quadratic employment adjustment cost function. As previously mentioned, this specific form of the adjustment cost function has been criticized in the literature. The chief critique is that there is a fixed cost of employment adjustment that cannot be captured by the model's quadratic form. Labor economists agree that some fixed costs are incurred regardless of the magnitude of employment adjustment. We claim that for the large firms we investigate, fixed costs are small enough relative to variable costs that we can ignore this criticism. In other words, we assume that the quadratic cost function can reasonably approximate the actual costs of these firms. Final judgment regarding the appropriateness of our assumption rests with the reader.

Another criticism of this type of adjustment cost specification is that it treats the costs of both an increase and a decrease in employment levels symmetrically. It is difficult to say a priori that employment adjustment in one direction is always more costly than employment adjustment in the 
other direction. This is an empirical question to be answered by the data. We test this cost asymmetry hypothesis by examining whether the partial adjustment parameter differs with the direction of the employment change. We omit a detailed presentation of the results for the sake of brevity and simply report here that our data reject the asymmetric adjustment cost hypothesis. The following analysis assumes a symmetric cost structure.

A final qualification regarding our model concerns the choice of the labor cost variable. It is common to use wage or salary data to measure the relative price of labor. We run our estimation using both this conventional measure and the factor-price measure that we prefer, total labor costs. We can then compare the results, although we have strong reservations about the appropriateness of the conventional measure for our specific analysis. We again omit a detailed presentation of these results for the sake of brevity and simply note that the two specifications yield similar results. However, the overall fit of the model is much better when total labor costs are used as the factor price of labor.

\subsubsection{Estimation of the Model Using Total Labor Costs}

It is sensible for firms to consider nonwage employment expenses, such as compulsory and noncompulsory benefits, when making hiring decisions. This is particularly true given that these costs as a share of total employment costs have increased in recent years. For example, by 1995 the share of nonwage benefits in total employment costs in the manufacturing industry as a whole was 14.5 percent (Okui 2000, figs. 1 and 2).

We therefore replace wages with total labor costs as a measure of the factor price of labor and estimate the following partial employment adjustment model for the entire sample of thirty-three firms.

$$
\begin{aligned}
& \text { (1) } \Delta \ln N_{t}=\lambda a_{1}+\lambda \ln \left(N_{t-1}\right)+\lambda a_{2} \ln \left(X_{t}\right)+\lambda a_{3} \ln \left(\frac{W_{t}}{P_{t}}\right)+\lambda a_{4} T+v \\
& \text { (2) } \ln N_{t}^{*}=a_{1}+a_{2} \ln \left(X_{t}\right)+a_{3} \ln \left(\frac{W_{t}}{P_{t}}\right)+a_{4} T
\end{aligned}
$$

where $N$ is actual employment, $N^{*}$ is desired employment, $X$ is output, ${ }^{5} \mathrm{~W}$ is total labor cost, $P$ is output price, ${ }^{6} T$ is time (year), and $\lambda$ is the partial adjustment parameter.

The results are summarized in table 5.3. Each column corresponds to a particular firm, and each row contains parameter estimates and $t$-values for a specific explanatory variable. The results are quite striking given the rather poor performance of the model when the conventional wage variable is used as the measure of the factor price. From equations (1) and (2), 


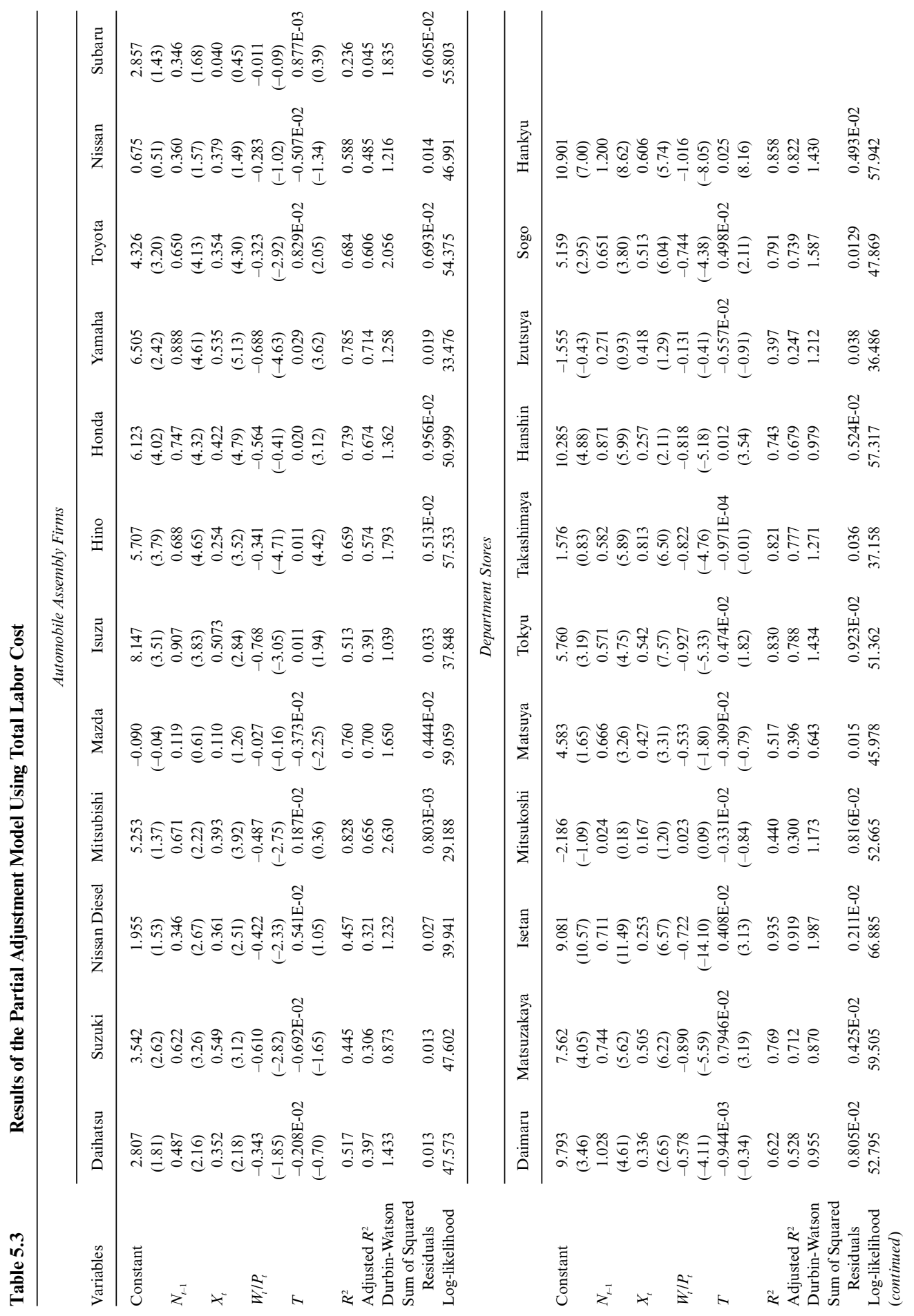




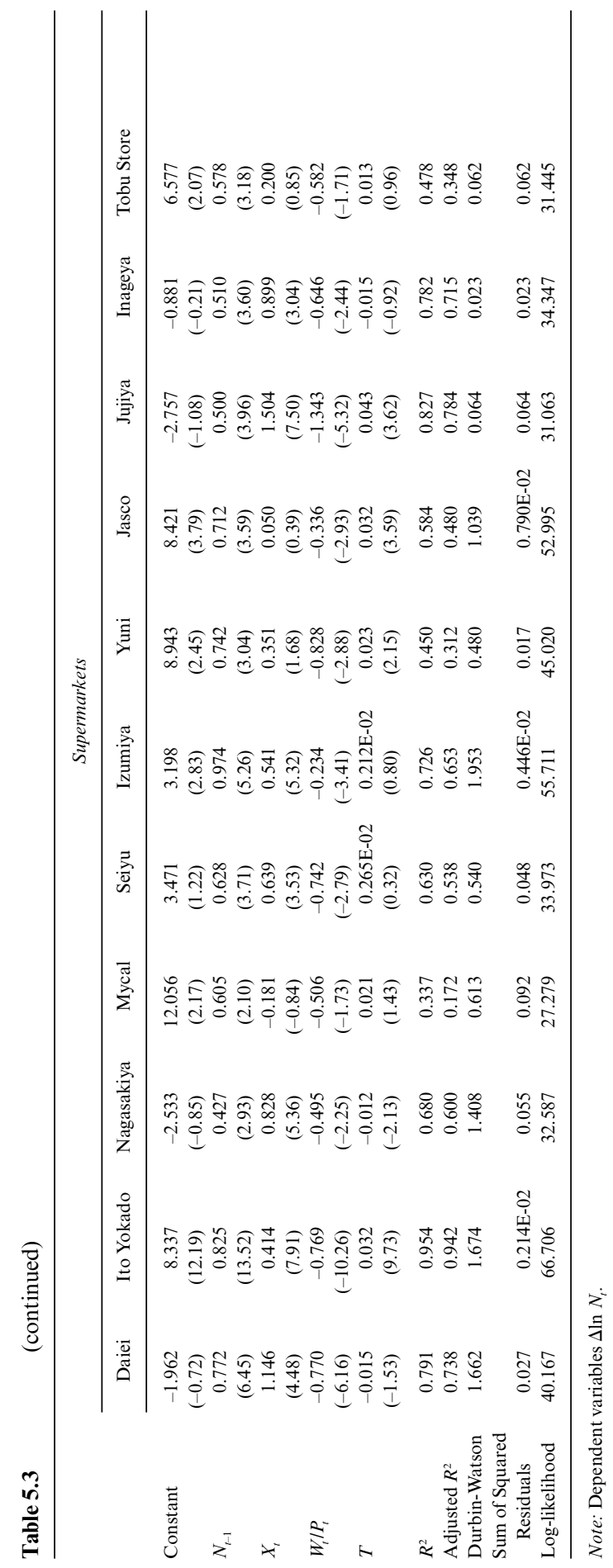


we know that the coefficients of $N_{t-1}, X_{t}$, and $W_{t} / P_{t}$ represent a partial adjustment parameter $(\lambda)$, a short-term output elasticity $\left(\lambda a_{2}\right)$, and a shortrun wage elasticity $\left(\lambda a_{3}\right)$, respectively. Therefore, we expect

$$
0 \leq \lambda \leq 1,0<\lambda a_{2}, 0<-\lambda a_{3} .
$$

These three parameters have the expected signs and are statistically significant for almost every firm. In addition, the model's ability to explain the variation in employment changes is dramatically improved by use of our factor price measure. The adjusted $R$-squared exceeds 0.5 in most cases, which is almost twice that of the model using the conventional wage measure. Simply put, the partial employment adjustment model can explain much of the employment adjustment behavior of leading Japanese firms. This casts significant doubt on the conventional wisdom that large Japanese firms have abided by a noneconomic commitment to employment stability for their regular employees.

\subsection{Estimation Results}

\subsubsection{Interindustry Analysis}

We reorganized the estimation results in table 5.3 to produce table 5.4, which shows partial adjustment coefficients, long-run output elasticities, and long-run wage elasticities. We now investigate interindustry variation in employment adjustment behavior by comparing industry average of adjustment coefficients. The estimates of the employment adjustment coefficient, $\lambda$, do not differ much across industries. They range from 0.569 for automobile assembly firms to only 0.670 for supermarkets. This range of only 0.10 does not change when we look at the means of only the statistically significant coefficients. This new range of estimates is virtually the same, varying from 0.667 for automobile assembly firms to 0.780 for department stores. These adjustment coefficients are much larger than those estimated by macrodata, which is consistent with the findings in table 5.2.

By contrast, the industry means of the long-run elasticities, particularly the output elasticity, diverge somewhat. The industry means of the wage elasticity range from 0.670 for automobile firms to 1.089 for supermarkets, although the range shrinks to 0.300 when only statistically significant elasticities are included. Similarly, the industry-specific means of the output elasticities vary from 0.665 for automobile firms to 1.319 for department stores. The range of these means increases when we include only the statistically significant elasticities. However, the industry order for the means remains the same. Automobile assembly firms have the smallest mean, followed by department stores and then supermarkets.

We test whether the industry differences in elasticities are statistically significant by pooling the data and running the employment adjustment 


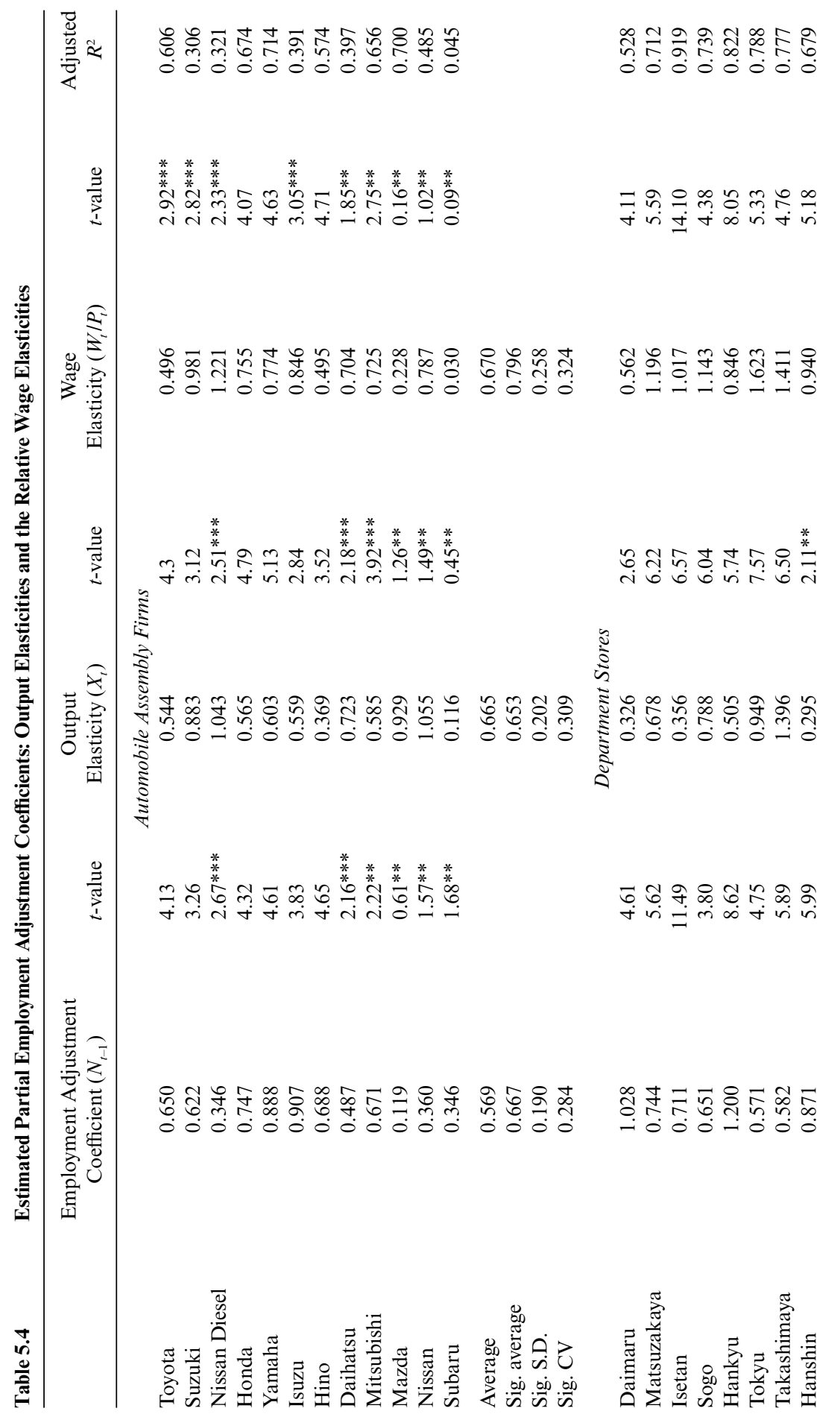




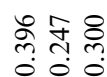

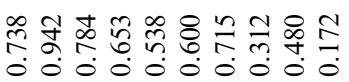

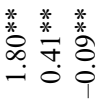

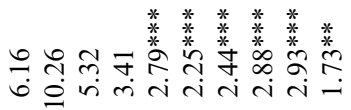

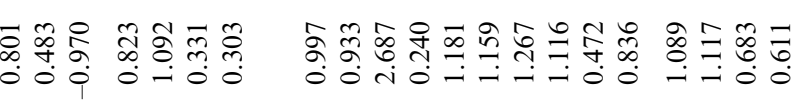

旁意

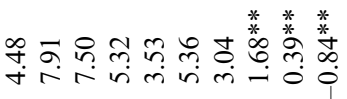

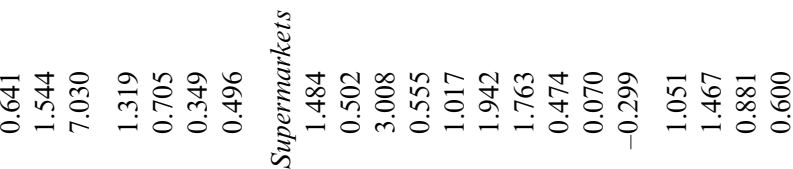

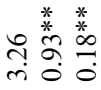

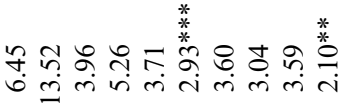

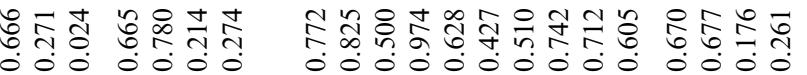

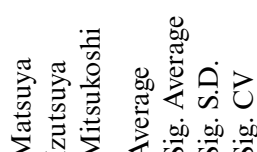

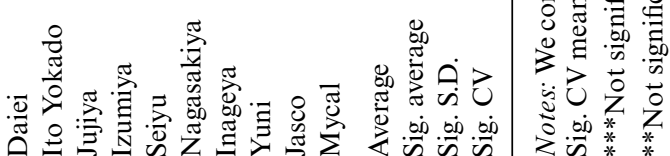

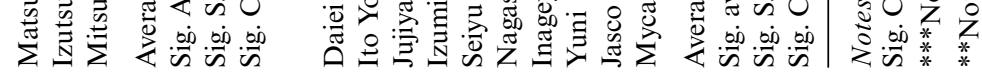


equations with industry dummies. We perform three pairwise comparisons (one for each pair of industries) and a tri-industry comparison. The results, shown in table 5.5, confirm the results of table 5.4. The adjustment speed, $\lambda$, is not statistically different between automobile firms and department stores or automobile firms and supermarkets. ${ }^{7}$ It is, however, significantly different between department stores and supermarkets. The two elasticities, on the other hand, are significantly different for all three pairs-automobile firms versus department stores, automobile firms versus supermarkets, and department stores versus supermarkets. We therefore conclude that the two elasticities, which represent production specificity, differ across industries. Industries are not so different, however, in their speed of employment adjustment. This suggests that there are similarities in the employment practices of leading Japanese firms across industries.

\subsubsection{Intraindustry Analysis}

The first thing to notice is the low variation in the estimated coefficients across firms. The coefficient of variations $(\mathrm{CV})$ of the respective parameter estimates, shown at the bottom of the panels in table 5.4, are calculated by the statistically significant coefficients only. The CVs for adjustment parameters lie between 0.26 and 0.29 . This relatively small variation in the estimated adjustment parameters further supports our interpretation of the interindustry adjustment parameters. The interfirm similarity of the employment adjustment parameters suggests that employment practices are similar, this time across leading Japanese firms within an industry.

The second thing to notice is the differences among supermarket companies in the two long-run elasticities. The CVs of the two elasticities exceed 0.6. In contrast, the CVs of the two elasticities for automobile assemblers are barely larger than that of the adjustment parameter. The CVs of the elasticities for department stores fall between the other two sectors: There are some differences in the long-run output elasticities, but the relative wage elasticities are very similar. These results suggest that the production frontiers of manufacturing firms, which produce similar products, are similar. There are much greater differences in the production frontiers of retail firms, which likely reflect the numerous choices retail managers must make when deciding how to sell their products.

The third thing to notice is that the relationship between the two elasticities is striking. Panel A of figure 5.1 plots both elasticities for each firm. There is clearly a positive relationship: A firm with a large output elasticity tends to have a large wage elasticity as well. Similarly, a firm with a small output elasticity tends to have a small wage elasticity. This positive relationship is observed for each industry as well as for the three industries as a group. The correlation coefficients of the elasticities are 0.917, 0.790,

7. It is noteworthy that the adjustment speed is much slower than those in table 5.4. 


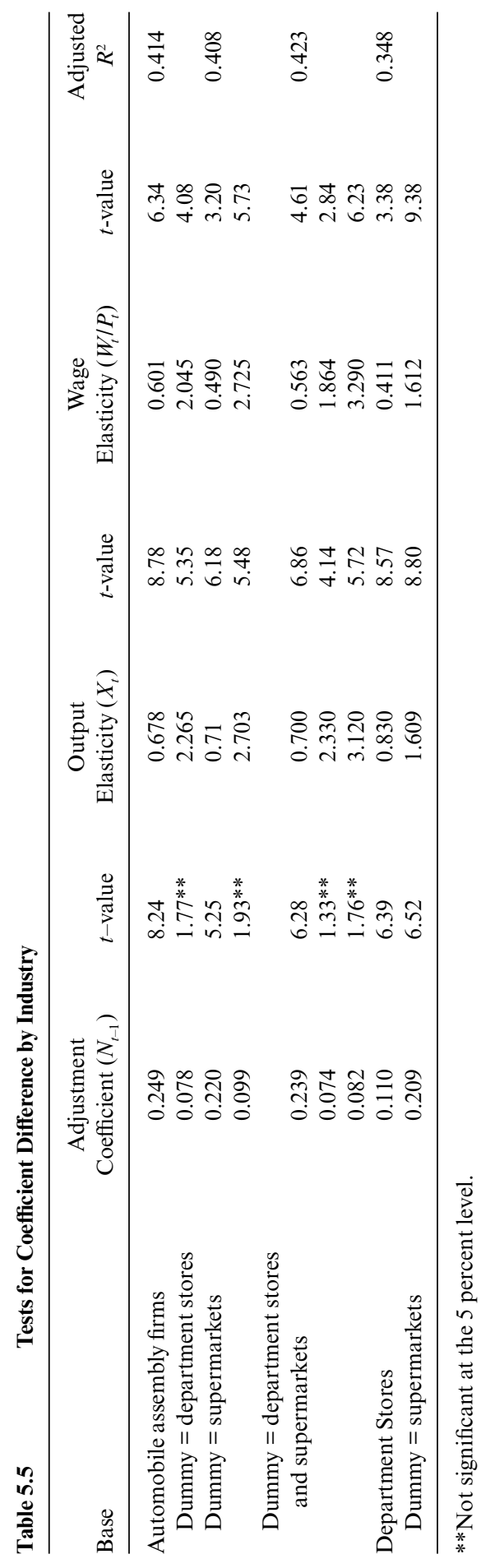


A

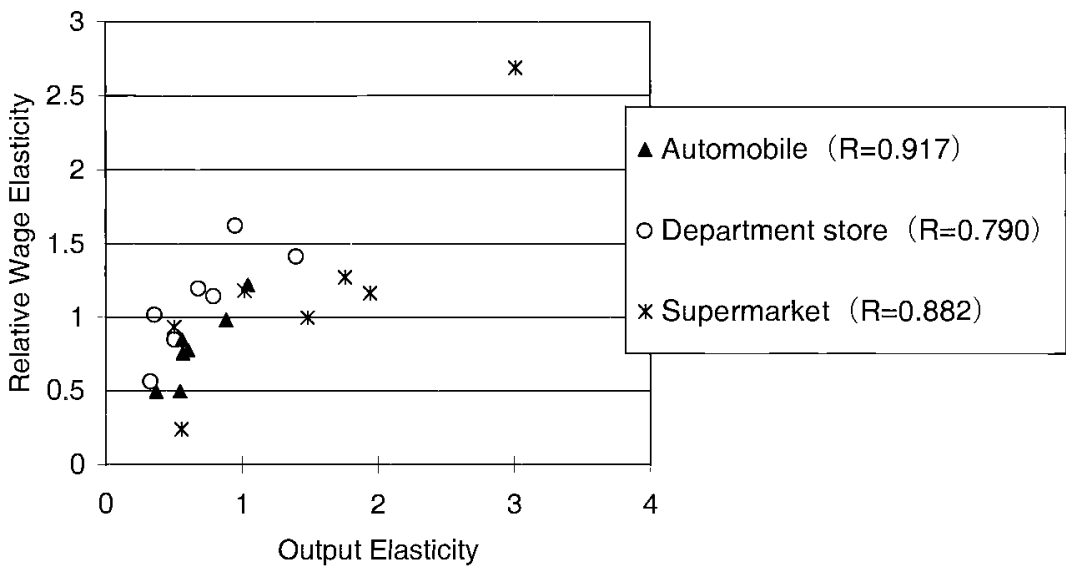

B

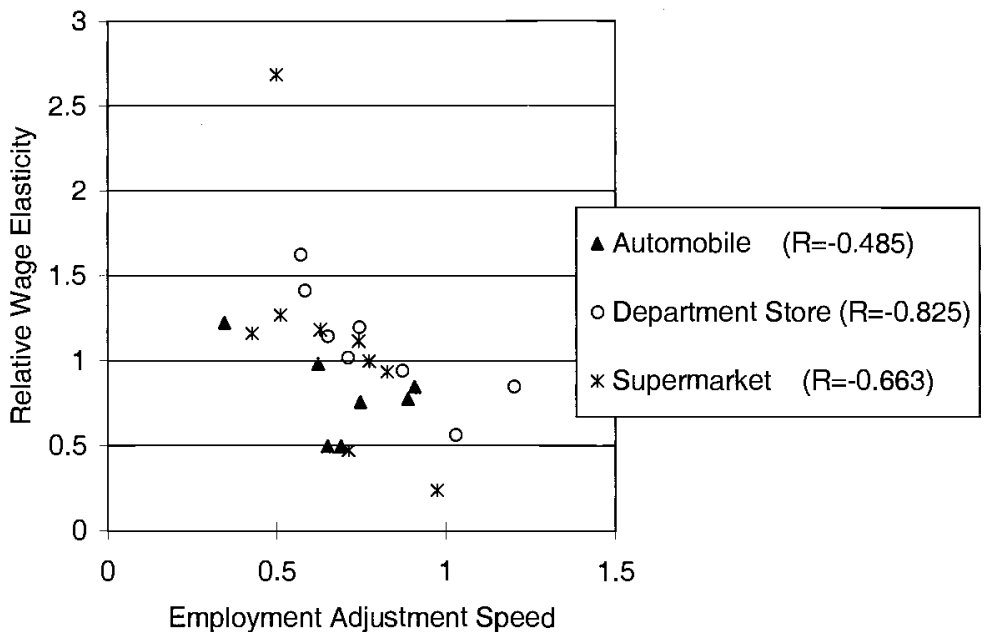

C

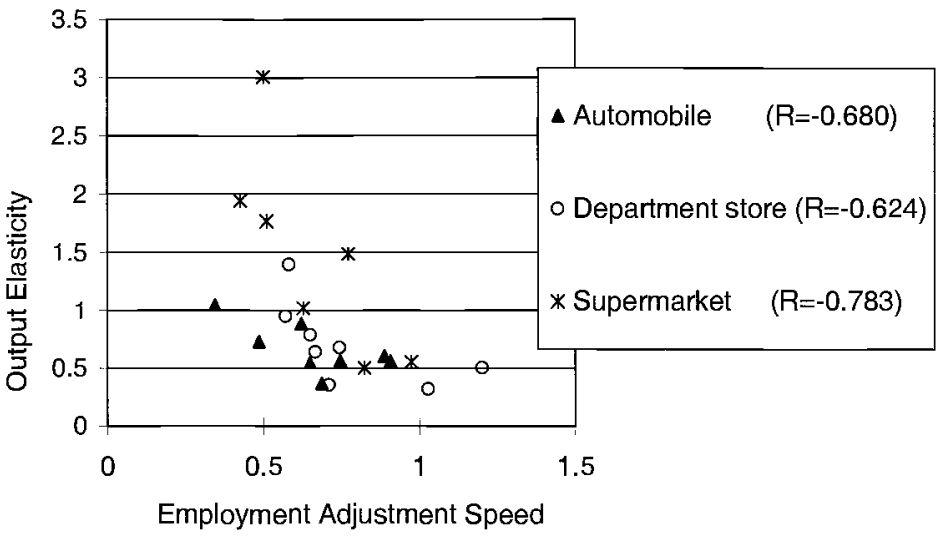

Fig. 5.1 Within-industry correlations: $A$, Correlation between wage and output elasticities; $B$, Correlation between wage elasticity and employment adjustment speed; $C$, Correlation between output elasticity and employment adjustment speed 
and 0.882 for automobile assembly firms, department stores, and supermarkets, respectively.

The last point is that the adjustment parameter has a negative relationship with the two elasticities. Panels B and C of figure 5.1 show that a firm with a large wage or output elasticity tends to have a small adjustment parameter. This relationship is observed for each industry, although the relationship is stronger when all three industries are pooled together. If we take the production frontier or its factor demand revelation in the two elasticities as given, we can interpret this negative relationship as the firm's compensating for the slow long-run adjustment of labor demand to relative wage or output changes by speeding up the short-run employment adjustment. If this interpretation is accurate, there is a complementarity between the industry's technology frontier and its labor management practices. We believe that this possibility merits further investigation.

\subsection{The Partial Adjustment Model Using Total Labor Input}

\subsubsection{The Necessity of Total Labor Input Analysis}

Our final task in this paper is to examine the applicability of the partial employment adjustment model to total labor input fluctuations in our sample firms. We have two motivations for this extension.

The first is that total labor input is a better measure of a firm's labor usage than are employment levels. It is reasonable to assume that there will be periods during which a given number of employees work longer or shorter hours as firms produce more or less output, respectively. Thus, labor input is best captured using work hours. Figure 5.2 shows both the change in sales and the change in total labor input at Nissan. The parallel movements of these two series suggest that this is indeed true.

The second is that, as figure 5.2 reveals, there are huge fluctuations in actual work hours in our sample. Thus, it is inaccurate to assume that employment levels fully capture a firm's total labor input. Average actual annual work hours of Federation of Japan Automobile Workers Unions (JAW) members at all eleven sample automobile firms were obtained thanks to the generosity of the JAW. Their understanding of the significance of our research is greatly appreciated.

\subsubsection{Estimation Results}

Table 5.6 presents the results of a modified partial adjustment analysis of total labor input. We substituted our total labor input variable, which is the product of employment and JAW work hours, for the typically used employment variable. We also replaced average annual total labor costs with hourly values.

The results again show an improvement in the overall fit of the employ- 


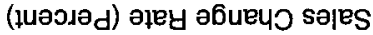

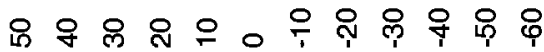

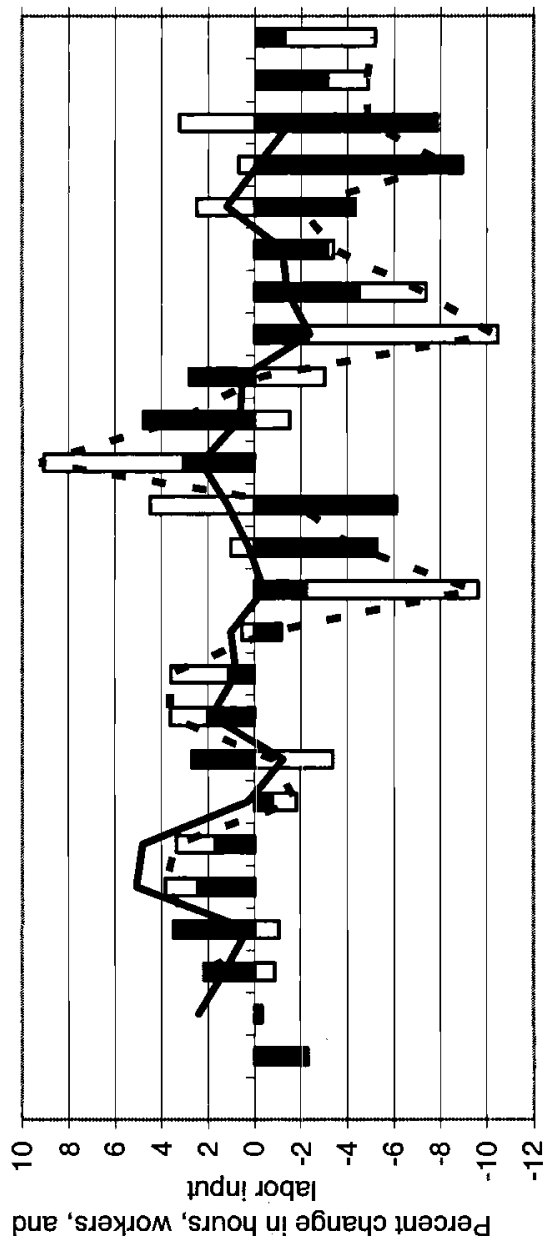

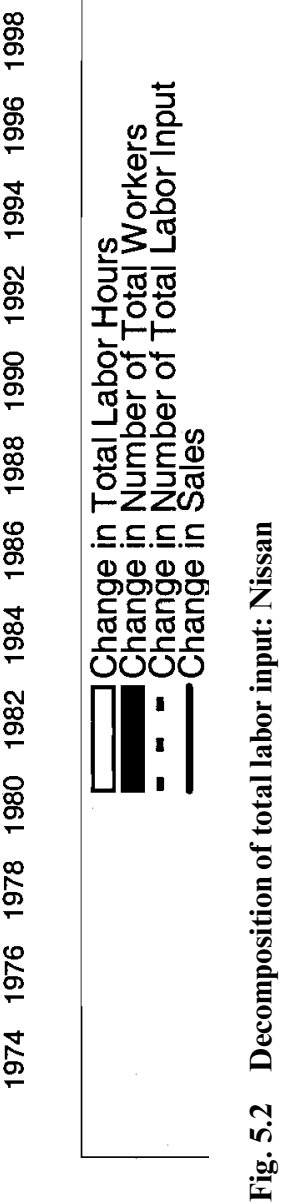




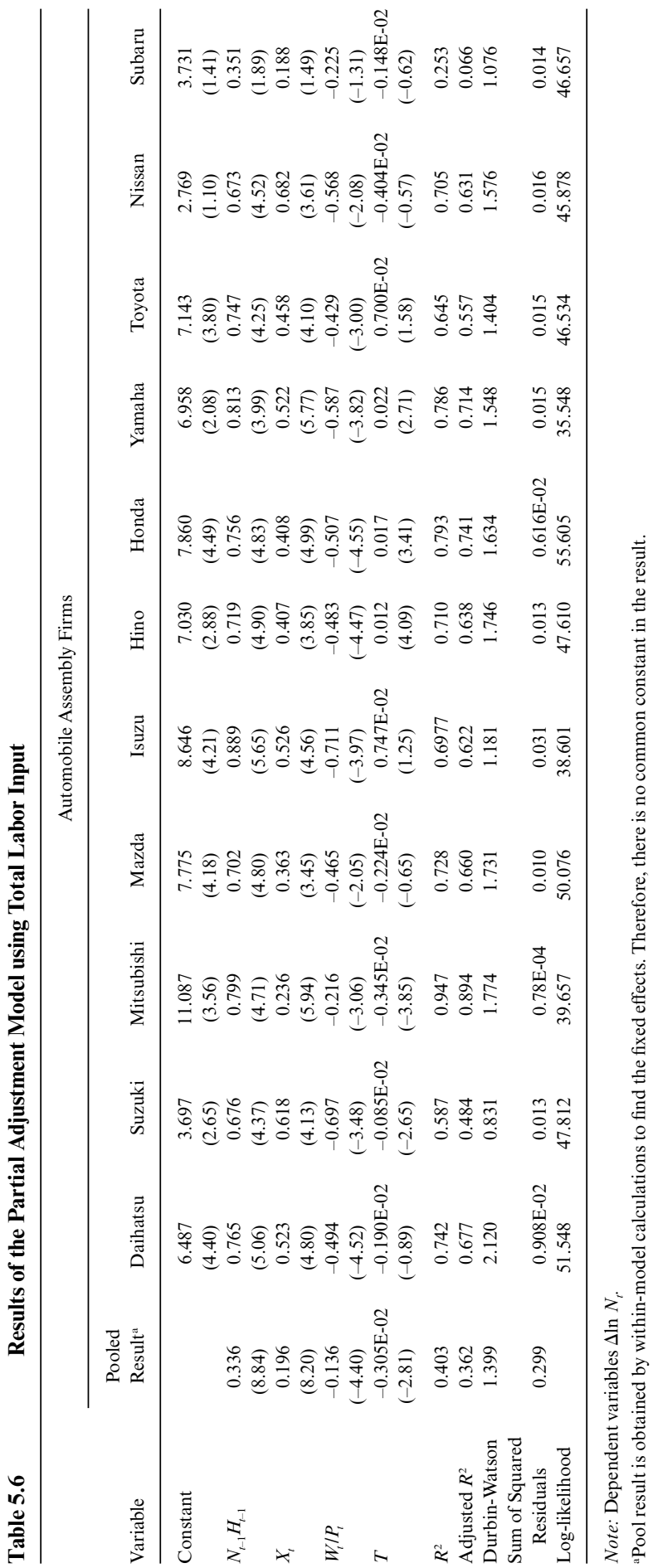


ment adjustment model for most firms when they are compared to those in table 5.3. The adjusted $R$-squared increases for eight of the eleven firms. The number of statistically significant parameters increases. Also, there is an increase in the partial adjustment parameter of most firms. The average partial adjustment parameter exceeds 0.7 , and the incremental increase serves to bring each firm's parameter closer to 1 . Again, these findings support our contention that leading Japanese firms follow conventional employment adjustment practices. They adjust both employment levels and work hours in response to fluctuations in output and the relative price of labor.

\subsection{Conclusion}

This paper investigates employment adjustment in leading Japanese firms. Specifically, we accomplish the following four tasks:

1. We construct a twenty-five-year, firm-level panel data set for thirtythree major Japanese firms in three industries: automobile manufacturing, department stores, and supermarkets. The data set includes consistent employment data on regular full-time workers. We use this data set to examine the accuracy of the commonly held belief that large Japanese firms make an employment commitment to their workers. By studying the frequency and magnitude of employment adjustments, we find that largescale employment adjustment is not at all uncommon among these firms and that the conventional wisdom is not supported by empirical evidence.

2. We use a partial employment adjustment model to explain the observed employment fluctuations. We use per capita total labor costs in place of average monthly salary as a measure of the factor price of labor. This model explains the employment adjustment behavior of leading Japanese firms very well.

3 . We find negative relationships between the adjustment parameter and the output and wage elasticities of employment for each industry separately and as well as for all three industries together. We interpret this negative relationship as evidence that firms compensate for slow long-run adjustment of labor demand to changes in relative wage or output by speeding up short-run employment adjustment. If this interpretation is accurate, there is a complementarity between an industry's technology frontier and its labor management practices in the three industries we study.

4. We use information on work hours, available for eleven automobile firms, to construct total labor input data. This enables us to apply the partial adjustment model to fluctuations in total labor input. The results show an improvement in the overall fit of the employment adjustment model for most firms. 
In conclusion, our findings suggest that the employment adjustment practices of leading Japanese firms reflect basic economic principles. Firms adjust employment levels and work hours in response to fluctuations in output and the relative price of labor.

\section{References}

Hamermesh, Daniel. 1989. Labor demand and the structure of adjustment costs. American Economic Review 79 (4): 674-89.

Kurosaka, Yoshiou. 1988. Makuro keizaigaku to Nihon no roudou shijyo (Macro economics and the Japanese labor market). Tokyo: Keizai Shinposya.

Ministry of Finance. Various years. Yukashouken hokusyo soran. Tokyo: Ministry of Finance.

Muramatsu, Kuramitsu. 1983. Nihon no roudou shijyo bunseki (An analysis of the Japanese labor market). Tokyo: Hakuto Syobou.

Nakata, Yoshifumi, and Ryoji Takehiro. 2001. Joint accounting system and human resource management by company group. Japan Labor Bulletin 40 (10): 5-11.

Noda, Tomohiko. 1998. Rodokumiai to koyochosei-Kigyo panel data ni yoru bunseki. (Labor union and employment adjustment-An analysis of firm panel data). Kenzai Kenkyu 49 (4): 317-326.

Noda, Tomohiko, and Junko Urasaka. 2001. Kigyotouchi to koyochousei (The effect of corporate governance on employment adjustment in Japanese manufacturing firms). Japanese Journal of Labour Studies 488:52-63.

Okui, Megumi. 2000. Jyoujyou kigyo no koyouchouseikeisuu no suitei. (Estimation of employment adjustment coefficient for those whose stocks are listed in the Japanese stock exchange markets). Kanazawa Gakuin University, Business Administration and Information Science Department. Mimeograph.

Smith, David J., and Stephen Karlson. 1991. The effect of fringe benefits on employment fluctuations in U.S. automobile manufacturing. Review of Economics and Statistics 73 (1): 40-49.

Suruga, Terukazu. 1997. Nihon kigyo no koyochosei. (Employment adjustment of Japanese firms). In Koyokanko no Henkato Jyosei Roudou, ed. Hiroyuki Chuma and Terukazu Suruga, 13-46. Tokyo: Tokyo Daigaku Syuppan Kai. 
